\title{
In Vitro Activity of Doripenem (S-4661) against Multidrug-Resistant Gram-Negative Bacilli Isolated from Patients with Cystic Fibrosis
}

\author{
Yunhua Chen, ${ }^{1}$ Elizabeth Garber, ${ }^{1}$ Qiuqu Zhao, ${ }^{1}$ Yigong Ge, ${ }^{2}$ Matthew A. Wikler, ${ }^{2}$ \\ Koné Kaniga, ${ }^{2}$ and Lisa Saiman ${ }^{1 *}$ \\ Department of Pediatrics, Columbia University, New York, New York, ${ }^{1}$ and Peninsula Pharmaceuticals, \\ Inc., Alameda, California ${ }^{2}$
}

Received 12 November 2004/Returned for modification 12 January 2005/Accepted 9 February 2005

\begin{abstract}
Doripenem $50 \%$ inhibitory concentrations $\left(\mathrm{MIC}_{50}\right)$ and $90 \%$ inhibitory concentrations $\left(\mathrm{MIC}_{90}\right)$ for multidrugresistant strains of mucoid Pseudomonas aeruginosa $(n=200$ strains), nonmucoid $P$. aeruginosa $(n=200)$, and Burkholderia cepacia complex $(n=200)$ isolated from patients with cystic fibrosis were 8 and 32,8 and 64 , and 8 and $32 \mu \mathrm{g} / \mathrm{ml}$, respectively. Doripenem had somewhat better activity than established antimicrobial agents.
\end{abstract}

Patients with cystic fibrosis (CF) can be chronically infected with several pathogens, including Staphylococcus aureus, nontypeable Haemophilus influenzae, and $P$. aeruginosa; by 18 years of age, $80 \%$ of patients are infected with $P$. aeruginosa (3). With time, $P$. aeruginosa converts to a mucoid phenotype which often heralds deterioration in respiratory status. Approximately $4 \%$ of patients in the United States become infected with Burkholderia cepacia complex, which can be particularly virulent and is associated with increased mortality (4).

The aggressive use of oral, intravenous, and aerosolized antibiotics has substantially contributed to the increased life expectancy for patients with CF. Several classes of intravenously administered agents are available to treat patients with CF experiencing acute pulmonary exacerbations. However, there is a need for additional therapeutic agents, particularly for the treatment of multidrug-resistant gram-negative pathogens (8). Multidrug resistance in CF strains is defined as resistance to all of the agents in two of three classes of antibiotics, i.e., quinolones, aminoglycosides, and beta-lactam agents, including monobactams and carbapenems (9).

Doripenem is a carbapenem in clinical development for serious bacterial infections. It has potent in vitro activity against a wide range of gram-positive and gram-negative clinical isolates $(2,5,11)$ and in vivo efficacy in various animal models $(10)$. We studied the in vitro activity of doripenem against 600 multidrugresistant clinical strains of $P$. aeruginosa and $B$. cepacia complex isolated from patients with $\mathrm{CF}$ and compared its activity with seven other conventional antipseudomonal antibiotics.

These isolates were sent to the CF Referral Center at Columbia University, which has established a large collection of multidrug-resistant isolates from patients with $\mathrm{CF}$ in the United States. In all, 200 mucoid $P$. aeruginosa, 200 nonmucoid $P$. aeruginosa, and 200 B. cepacia complex strains isolated from 2001 through 2003 (each from a unique patient with CF) were tested in this study. Antimicrobial susceptibility testing was performed using a commercially prepared (TREK Diagnostic Systems, Cleveland, $\mathrm{OH}$ ) broth microdilution assay (6). The

\footnotetext{
* Corresponding author. Mailing address: Columbia University, 622 West 168th St., PH4W-470, New York, NY 10032. Phone: (212) 3059446. Fax: (212) 305-9491. E-mail: LS5@columbia.edu.
}

studies were not performed in replicate. Interpretative criteria for susceptibility breakpoints for non-Enterobacteriaceae, including $P$. aeruginos $a$ and $B$. cepacia, were used and are shown in Table 1 (7). The breakpoint for imipenem was used tentatively for doripenem for comparative purposes, because $\mathrm{Na}$ tional Committee for Clinical Laboratory Standards susceptibility criteria for doripenem are not yet available (7).

The activity of the eight antimicrobial agents against these clinical isolates is shown in Table 1. Overall, doripenem exhibited the lowest $50 \%$ inhibitory concentration $\left(\mathrm{MIC}_{50}\right)$ and lowest $90 \%$ inhibitory concentration $\left(\mathrm{MIC}_{90}\right)$ values $(8$ and 32 $\mu \mathrm{g} / \mathrm{ml}$ for mucoid $P$. aeruginosa, 8 and $64 \mu \mathrm{g} / \mathrm{ml}$ for nonmucoid $P$. aeruginosa, and 8 and $32 \mu \mathrm{g} / \mathrm{ml}$ for $B$. cepacia complex strains). The proportions of $P$. aeruginosa isolates susceptible to doripenem and tobramycin were comparable (40\% versus $49 \%$ of mucoid and $33 \%$ versus $34 \%$ of nonmucoid strains, respectively). Less than one-third of the $P$. aeruginosa strains were susceptible to imipenem (26\%), aztreonam, piperacillin, ceftazidime, and cefepime. Ceftazidime and doripenem were the two most active agents against $B$. cepacia complex strains, inhibiting $43 \%$ and $25 \%$, respectively.

In addition, we assessed cross-resistance between doripenem and tobramycin among $P$. aeruginosa strains, as tobramycin is frequently used for patients with CF. In all, 43\% (173 of 400) of $P$. aeruginosa strains were resistant to tobramycin (MIC $\geq$ $16 \mu \mathrm{g} / \mathrm{ml}$ ) and of these 173 strains, $54 \%$ were susceptible or intermediately susceptible to doripenem (MIC $\leq 8 \mu \mathrm{g} / \mathrm{ml}$ ). Similarly, 49\% (197 of 400) of strains were resistant to doripenem and of these 197 strains, 59\% were susceptible or intermediately susceptible to tobramycin.

The selected strains represent problematic clinical isolates for patients with $\mathrm{CF}$, as therapeutic options are limited because of multidrug resistance. These strains were obtained from patients across the United States, which supports the notion that multidrug resistance is widespread in this patient population. While accurate rates for multidrug-resistant strains of $P$. aeruginosa and $B$. cepacia complex are unavailable, from 1996 to 2003 the CF Referral Center (http://synergy.columbia .edu) processed approximately 20,000 strains from 6,700 patients from $140 \mathrm{CF}$ care centers in the United States.

Over the past several years, there has been increasing clin- 
TABLE 1. Activity of doripenem compared with conventional agents against 600 multidrug-resistant strains of $P$. aeruginosa and B. cepacia complex isolated from patients with cystic fibrosis

\begin{tabular}{|c|c|c|c|c|c|c|c|c|c|c|}
\hline \multirow{2}{*}{ Organism $^{a}$} & \multirow{2}{*}{$\begin{array}{c}\text { Antimicrobial } \\
\text { agent }\end{array}$} & \multirow{2}{*}{$\begin{array}{l}\text { MIC range } \\
(\mu \mathrm{g} / \mathrm{ml})^{b}\end{array}$} & \multicolumn{3}{|c|}{$\begin{array}{l}\text { MIC }(\mu \mathrm{g} / \mathrm{ml}) \text { breakpoint } \\
\text { interpretation }^{c}\end{array}$} & \multicolumn{3}{|c|}{ No. $(\%)$ of strains ${ }^{c}$} & \multirow{2}{*}{$\begin{array}{l}\mathrm{MIC}_{50} \\
(\mu \mathrm{g} / \mathrm{ml})\end{array}$} & \multirow{2}{*}{$\begin{array}{r}\mathrm{MIC}_{90} \\
(\mu \mathrm{g} / \mathrm{ml})\end{array}$} \\
\hline & & & $\mathrm{S}$ & I & $\mathrm{R}$ & $\mathrm{S}$ & I & $\mathrm{R}$ & & \\
\hline \multirow{8}{*}{$\begin{array}{l}\text { P. aeruginosa (mucoid; } \\
\quad n=200 \text { ) }\end{array}$} & Doripenem $^{d}$ & $0.25-512$ & $\leq 4$ & 8 & $\geq 16$ & $81(40)$ & $21(11)$ & $98(49)$ & 8 & 32 \\
\hline & Imipenem & $0.5-512$ & $\leq 4$ & 8 & $\geq 16$ & $60(30)$ & $12(6)$ & $128(64)$ & 32 & 128 \\
\hline & Tobramycin & $0.25->512$ & $\leq 4$ & 8 & $\geq 16$ & $98(49)$ & $33(16)$ & $69(35)$ & 8 & 64 \\
\hline & Aztreonam & $0.25->512$ & $\leq 8$ & 16 & $\geq 32$ & $40(20)$ & $17(9)$ & $143(71)$ & 64 & $>512$ \\
\hline & Piperacillin & $0.5->512$ & $\leq 64^{e}$ & N/A & $\geq 128$ & $54(27)$ & N/A & $146(73)$ & 512 & $>512$ \\
\hline & Ceftazidime & $0.5->512$ & $\leq 8$ & 16 & $\geq 32$ & $49(24)$ & $11(6)$ & $140(70)$ & 64 & $>512$ \\
\hline & Cefepime & $2->256$ & $\leq 8$ & 16 & $\geq 32$ & $27(13)$ & $30(15)$ & $143(72)$ & 64 & 256 \\
\hline & Levofloxacin & $0.25-512$ & $\leq 2$ & 4 & $\geq 8$ & $67(33)$ & $40(20)$ & $93(47)$ & 16 & 128 \\
\hline \multirow{8}{*}{$\begin{array}{l}\text { P. aeruginosa } \\
\quad(\text { nonmucoid; } n=200)\end{array}$} & Doripenem $^{d}$ & $0.25-512$ & $\leq 4$ & 8 & $\geq 16$ & $66(33)$ & 35 (18) & $99(49)$ & 8 & 64 \\
\hline & Imipenem & $0.5-512$ & $\leq 4$ & 8 & $\geq 16$ & $43(21)$ & $19(10)$ & $138(69)$ & 32 & 64 \\
\hline & Tobramycin & $0.5->512$ & $\leq 4$ & 8 & $\geq 16$ & $68(34)$ & $28(14)$ & $104(52)$ & 16 & 256 \\
\hline & Aztreonam & $0.25->512$ & $\leq 8$ & 16 & $\geq 32$ & $31(15)$ & $10(5)$ & $159(80)$ & 128 & $>512$ \\
\hline & Piperacillin & $1->512$ & $\leq 64^{e}$ & N/A & $\geq 128$ & $40(20)$ & N/A & $160(80)$ & 512 & $>512$ \\
\hline & Ceftazidime & $1->512$ & $\leq 8$ & 16 & $\geq 32$ & $32(16)$ & $17(8)$ & $151(76)$ & 128 & $>512$ \\
\hline & Cefepime & $4->256$ & $\leq 8$ & 16 & $\geq 32$ & $21(10)$ & $22(11)$ & $157(79)$ & 64 & 256 \\
\hline & Levofloxacin & $0.25-512$ & $\leq 2$ & 4 & $\geq 8$ & $29(14)$ & $52(26)$ & $119(60)$ & 16 & 128 \\
\hline \multirow[t]{8}{*}{ B. cepacia $(n=200)$} & Doripenem $^{d}$ & $0.5-256$ & $\leq 4$ & 8 & $\geq 16$ & $50(25)$ & $53(26)$ & $97(49)$ & 8 & 32 \\
\hline & Imipenem & $0.25-256$ & $\leq 4$ & 8 & $\geq 16$ & $18(9)$ & $14(7)$ & $168(84)$ & 32 & 128 \\
\hline & Tobramycin & $0.25->512$ & $\leq 4$ & 8 & $\geq 16$ & $4(2)$ & $4(2)$ & $192(96)$ & 256 & $>512$ \\
\hline & Aztreonam & $4->512$ & $\leq 8$ & 16 & $\geq 32$ & $15(7)$ & $10(5)$ & $175(88)$ & $>512$ & $>512$ \\
\hline & Piperacillin & $1->512$ & $\leq 16^{e}$ & $32-64$ & $\geq 128$ & $38(19)$ & $36(18)$ & $126(63)$ & 256 & $>512$ \\
\hline & Ceftazidime & $1->512$ & $\leq 8$ & 16 & $\geq 32$ & $86(43)$ & $30(15)$ & $84(42)$ & 16 & $>512$ \\
\hline & Cefepime & $2->256$ & $\leq 8$ & 16 & $\geq 32$ & $21(10)$ & $17(9)$ & $162(81)$ & 256 & $>256$ \\
\hline & Levofloxacin & $0.25-512$ & $\leq 2$ & 4 & $\geq 8$ & $46(23)$ & $16(8)$ & 138 (69) & 16 & 128 \\
\hline
\end{tabular}

\footnotetext{
${ }^{a}$ Numbers in parentheses represent the number of strains.

${ }^{b}$ The range of MICs tested for all agents was 0.25 to $512 \mu \mathrm{g} / \mathrm{ml}$, except for cefepime (0.25 to $\left.256 \mu \mathrm{g} / \mathrm{ml}\right)$.

${ }^{c}$ Abbreviations used in table: S, susceptible; I, intermediate; R, resistant; N/A, no intermediate range for $P$. aeruginosa.

${ }^{d}$ Breakpoint for imipenem was used tentatively for doripenem, as NCCLS susceptibility criteria for doripenem are not yet available.

$e^{e} \leq 64$ for $P$. aeruginosa, $\leq 16$ for $B$. cepacia.
}

ical experience with carbapenem antibiotics for patients with CF. Much of this interest has focused on meropenem for management of acute pulmonary exacerbations, in part because of its superior activity against $B$. cepacia complex and because of its activity against multidrug-resistant strains of $P$. aeruginosa (1). Overall, we have noted that $40 \%$ of multidrugresistant strains of $P$. aeruginosa and $29 \%$ of B. cepacia complex strains processed by the CF Referral Center are susceptible to meropenem (L. Saiman, unpublished data). In this study, comparable proportions of $P$. aeruginosa (37\%) and $B$. cepacia complex strains (25\%) were susceptible to doripenem.

In conclusion, doripenem exhibited somewhat better in vitro activity against multidrug-resistant strains isolated from patients with $\mathrm{CF}$ than other conventional antipseudomonal agents. Future studies of doripenem should assess the inhibitory effect of $\mathrm{CF}$ sputum on doripenem's potency, the pharmacokinetics of doripenem in patients with $\mathrm{CF}$, and the concentration of doripenem achievable within the lung following intravenous administration. Such studies would support the potential role of doripenem for treatment of acute pulmonary exacerbations associated with $P$. aeruginosa and $B$. cepacia complex, particularly when combined with another effective agent.

This work was funded by Peninsula Pharmaceuticals Inc.

\section{REFERENCES}

1. Blumer, J., L. Saiman, M. W. Konstan, and D. Melnick. The efficacy and safety of meropenem and tobramycin versus ceftazidime and tobramycin in the treatment of acute pulmonary exacerbations in patients with cystic fibrosis. Chest, in press.

2. Ge, Y., M. A. Wikler, D. F. Sahm, R. S. Blosser-Middleton, and J. A. Karlowsky. 2004. In vitro antimicrobial activity of doripenem, a new carbapenem. Antimicrob. Agents Chemother. 48:1384-1396.

3. Gilligan, P. H. 1991. Microbiology of airway disease in patients with cystic fibrosis. Clin. Microbiol. Rev. 4:35-51.

4. LiPuma, J. J. 1998. Burkholderia cepacia epidemiology and pathogenesis: implications for infection control. Curr. Opin. Pulm. Med. 4:337-341.

5. Mushtaq, S., Y. Ge, and D. M. Livermore. 2004. Comparative activities of doripenem versus isolates, mutants, and transconjugants of Enterobacteriaceae and Acinetobacter spp. with characterized beta-lactamases. Antimicrob. Agents Chemother. 48:1313-1319.

6. National Committee for Clinical Laboratory Standards. 2002. NCCLS document M100-S12: performance standards for antimicrobial susceptibility testing. Twelfth informational supplement, p. 43-44. NCCLS, Wayne, PA.

7. National Committee for Clinical Laboratory Standards. 2004. NCCLS document M100-S14: performance standards for antimicrobial susceptibility testing. Fourteenth informational supplement, vol. 24 (No. 1), p. 36-38, 102-104. NCCLS, Wayne, PA.

8. Saiman, L., F. Mehar, W. W. Niu, H. C. Neu, K. J. Shaw, G. Miller, and A. Prince. 1996. Antibiotic susceptibility of multiply resistant Pseudomonas aeruginosa isolated from patients with cystic fibrosis, including candidates for transplantation. Clin. Infect. Dis. 23:532-537.

9. Saiman, L., J. Siegel, and the CF Foundation Consensus Conference on Infection Control Participants. 2003. Infection control recommendations for patients with cystic fibrosis: microbiology, important pathogens, and infection control practices to prevent patient-to-patient transmission. Infect. Control Hosp. Epidemiol. 24:S1-S52.

10. Tsuji, M., Y. Ishii, A. Ohno, S. Miyazaki, and K. Yamaguchi. 1998. In vitro and in vivo antibacterial activities of S-4661, a new carbapenem. Antimicrob Agents Chemother. 42:94-99.

11. Watanabe, A., H. Takahashi, T. Kikuchi, T. Kobayashi, K. Gomi, S. Fujimura, Y. Tokue, and T. Nukiwa. 2000. Comparative in vitro activity of S-4661, a new parenteral carbapenem, and other antimicrobial agents against respiratory pathogens. Chemotherapy 46:184-187. 